\title{
BMJ Open Bibliometric analysis of scientific publications in transplantation journals from Mainland China, Japan, South Korea and Taiwan between 2006 and 2015
}

\author{
Qiang-Hong Pu, Qiu-Ju Lyu, Huai-Yu Su
}

To cite: Pu Q-H, Lyu Q-J, Su H-Y. Bibliometric analysis of scientific publications in transplantation journals from Mainland China, Japan, South Korea and Taiwan between 2006 and 2015. BMJ Open 2016;6:e011623. doi:10.1136/bmjopen-2016011623

- Prepublication history for this paper is available online. To view these files please visit the journal online (http://dx.doi.org/10.1136/ bmjopen-2016-011623)

Q-HP and Q-JL contributed equally.

Received 23 February 2016 Revised 16 May 2016 Accepted 12 July 2016

\section{CrossMark}

People's Hospital of Leshan, Leshan, Sichuan, People's Republic of China

Correspondence to Huai-Yu Su; sclsshy@hotmail.com

\section{ABSTRACT}

Objectives: The aim of this study is to compare the quantity and quality of scientific publications in transplantation fields that were written by researchers from Mainland China, Japan, South Korea and Taiwan in the East Asia region.

Settings: East Asia.

Participants and outcome measures: Articles except editorials, conference abstracts, letters, news and corrections published in 25 transplantation journals from 2006 to 2015 were screened with the Web of Science database. The number of total and annual articles, article types (study design and transplantation site), impact factor, citations and articles in the high-impact journals was determined to assess the quantity and quality of transplantation research from East Asia. The correlation of socioeconomic factors and annual publications was also analysed.

Results: From 2006 to 2015, there were 47141 articles published in transplantation journals, of which researchers from Japan published 3694 articles, followed by Mainland China, South Korea and Taiwan with 2778, 1643 and 951 articles, respectively. Similar trends were observed in accumulated impact factor, accumulated citations, articles in the high-impact journals and articles on transplantation site. Publications from Japan had the highest average impact factor and citation, while those from Mainland China had the lowest. Additionally, in terms of study design, authors from Mainland China contributed to most clinical trials and randomised controlled trials, but authors from Japan contributed to most case reports. The annual numbers of articles from Mainland China and South Korea increased linearly $(p<0.05)$, but those from Japan and Taiwan remained stable for the period studied. The annual numbers of articles from Mainland China and South Korea were positively correlated with gross domestic product $(p<0.05)$.

Conclusions: Transplantation research productivity in East Asia is highly skewed, with gross domestic product having a significant positive correlation. Mainland China still lags far behind Japan in most bibliometric indicators; thus, there is vast room for improvement.

\section{Strengths and limitations of this study}

- This bibliometric analysis compared the quantity and quality of scientific publications in the transplantation field from Mainland China, Japan, South Korea and Taiwan in the East Asia region.

- A limitation of this study is that the journals in our analysis were selected from the transplantation category of the Science Citation Index Expanded (2015), but some relevant journals were excluded in this index.

- Another limitation of this study is that all articles in the transplantation field are from the Web of Science database, so articles published in a non-Web of Science database will be omitted.

\section{INTRODUCTION}

Now many end-stage diseases, such as hepatocellular carcinoma, serious renal failure and heart failure, are common diseases that pose a serious threat to public health. Many patients died from serious loss of organ function and life-threatening complications. Organ or tissue transplantation is an indispensable treatment for end-stage diseases. As an example of organ transplantation, only in 2010 the number of registered organ transplantations had reached over 100000 cases worldwide. According to data from the Global Observatory on Donation and Transplantation (GODT) and the Taiwan Organ Registry and Sharing Center (TORSC), Mainland China in the East Asia region contributed to the most cases, totalling 8000 , followed by South Korea, Taiwan and Japan with about 2500, 800 and 300 cases, respectively, in 2010. Therefore, transplantation is a growing scientific field and there was a rapid rise in scientific publications in the transplantation field. ${ }^{1-3}$ However, assessment of scientific research products in 
the transplantation field was still scarce. ${ }^{1-4}$ Furthermore, there is no previous report on the assessment of scientific research output on transplantation originating from the East Asia region. Therefore, bibliometric analysis of research output in transplantation from the East Asia region should be worthy.

Bibliometrics is an important tool to measure scientific output of an individual, institution or country using relevant parameters including quantity, impact factor and citation of published articles. Bibliometric analysis of research output is necessary to assess the current research status and country's contribution to specific fields, and also to guide the future research direction in specific research fields. To show the contribution of authors from Mainland China, Japan, South Korea and Taiwan in East Asia to transplantation research, we wanted to assess the quantity and quality of their scientific publications in transplantation journals between 2006 and 2015 using bibliometric methods. Additionally, there are many socioeconomic factors including gross domestic product (GDP), research and development expenditure and expenditure on healthcare that determine the quantity and quality of publications. ${ }^{5}{ }^{6}$ In terms of GDP, China, Japan, South Korea and Taiwan are the top four ranking countries in the East Asia region, and specifically China and South Korea experienced a rapid increase in GDP over the past 10 years. Therefore, we also investigated whether GDP influences transplantation research productivity from the four countries (areas).

\section{METHODS}

In this bibliometric study, we examined 25 journals that were selected from the transplantation category of the Science Citation Index Expanded (SCIE) provided by the Institute for Scientific Information (ISI). Although other transplantation articles may be published in other journals, publications in the 25 journals represent the majority of scientific research output in the transplantation field. The full names of 25 journals were used to perform the search in the Web of Science (WOS) database. Original articles and reviews from Mainland China, Japan, South Korea and Taiwan from January 2006 to December 2015 were included, since two types of publications basically reflect scientific output. Other types of publications such as editorials, letters to the editor, conference abstracts, news and corrections were excluded. Additionally, only English articles were included in this study. Search results were exported to two softwares Endnote and Microsoft office Excel, and duplicate publications were identified and removed using the following indicators such as author, title and abstract. The articles were identified to be research outputs from the four countries (areas) as long as the four countries' (areas') names (China, Japan, Korea and Taiwan) were listed in the author's affiliation. The articles will be classified by study design and transplantation site, respectively. In respect of study design, clinical trials, randomised controlled trials (RCT) and case reports, respectively, were generated according to publication types by PubMed, when the PubMed identifiers (PMIDs) of the above articles were imported into the PubMed database. If the PMIDs of the articles were not available, the study design of the articles was directly justified. In respect of transplantation site, articles on common organ transplantation including the kidney, heart, liver, lung and pancreas were investigated using the following method. To identify the related articles in the individual transplantation site, the Boolean separator 'AND' was included between the country (area) terms and transplantation site-specific terms listed in table 1 . The initial search results from each country (area) were further assessed to exclude the unrelated articles.

Data search and extraction were performed independently by two researchers (Q-JL and Q-HP), and discrepancy of results was resolved in a consensus meeting. All literature search and data extraction were completed on 24 April 2016 to avoid the fluctuation of the results owing to the update of the database.

To compare the quantity and quality of research articles, five methods were used. First, the total number and

\begin{tabular}{|c|c|}
\hline $\begin{array}{l}\text { Transplantation } \\
\text { site }\end{array}$ & Search terms \\
\hline Kidney & $\begin{array}{l}\text { TS=('kidney transplant"' OR 'kidney graft"' OR 'renal transplant"' OR 'renal graft"' OR 'kidney allograft"' } \\
\text { OR 'kidney allotransplant" OR 'renal allograft"' OR 'renal allotransplant") }\end{array}$ \\
\hline Heart & $\begin{array}{l}\text { TS=('heart transplant"' OR 'heart graft"' OR 'cardiac transplant" OR 'cardiac graft"' OR 'heart allograft" } \\
\text { OR 'heart allotransplant" OR 'cardiac allograft" OR 'cardiac allotransplant") }\end{array}$ \\
\hline Liver & 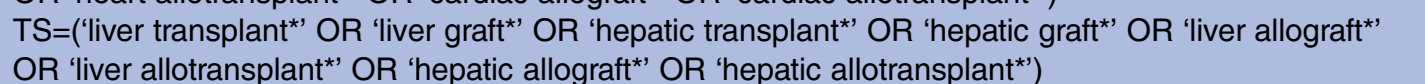 \\
\hline Lung & $\begin{array}{l}\text { TS=('lung transplant*' OR 'lung graft"' OR 'pulmonary transplant"' OR 'pulmonary graft"' OR 'lung } \\
\text { allotransplant" }\end{array}$ \\
\hline Pancreas & $\begin{array}{l}\text { TS=('pancreas transplant*' OR 'pancreas graft"' OR 'pancreatic transplant*' OR 'pancreatic graft"' OR } \\
\text { 'pancreas allotransplant"' OR 'pancreas allograft" OR 'pancreatic allotransplant"' OR 'pancreatic } \\
\text { allograft") }\end{array}$ \\
\hline
\end{tabular}


annual number of publications from Mainland China, Japan, South Korea and Taiwan were summarised, and if the annual publication number continuously increased, we compared linear and exponential fitting to assess whether the growth of scientific publications follows Price's law. ${ }^{7} 8$ Second, to clarify whether the socioeconomic factor GDP was a determinant for the number of published articles, the correlation analysis between GDP and annual publication number was investigated. GDP from 2005 to 2014 was used since the prior year fund usually supports the current year production (GDP data of Mainland China, Japan and South Korea from the World Bank and GDP data of Taiwan from the Statistics Bureau of Taiwan). Third, the accumulated and average impact factors were determined according to the Journal Citation Reports (JCR) 2014 provided by the ISI. The accumulated impact factor was calculated by multiplying the number of articles with the impact factor (JCR 2014) of the individual journal, and then summing up these data from the selected 25 journals between 2006 and 2015. The more articles one country (area) had, the higher accumulated impact factor one country (area) usually had. To assess more accurately the quality of published articles from one country (area), the average impact factor was introduced. The average impact factor was defined as the accumulated impact factor divided by the total number of published articles. Fourth, citation reports of published articles were also collected. Fifth, articles published in the top 10 high-impact transplantation journals were also compared, because the number of articles in high-impact journals often represents the research level of one country (area) in the specific field. Finally, the top 10 most popular journals for the four countries (areas) were analysed according to the number of published articles.

\section{STATISTICAL ANALYSES}

All data were analysed using the GraphPad Prism software (V.6, GraphPad Software Inc). Kruskal-Wallis tests were used to measure differences of quantitative data between the four countries (areas), and post hoc Dunn's multiple comparison tests were followed to detect the difference between two countries (areas) if necessary. All statistical tests were two-tailed and a $\mathrm{p}<0.05$ was considered to be statistically significant.

\section{RESULTS}

\section{Trends in the number of articles}

A total of 47141 transplantation articles were published in the selected 25 journals in the world from 2006 to 2015. As shown in table 2, authors from Japan produced the highest number of articles (3694, 7.8\%, 3rd in the world), followed by Mainland China (2778, 5.9\%, 6th), South Korea $(1643,3.5 \%, 11$ th) and Taiwan $(951,2.0 \%$, 19th). Japan and Mainland China jointly account for $\sim 70 \%$ of the articles. The proportions of articles in transplantation among all articles from all four countries (areas) were still minimal $(<0.5 \%$ of total articles). We observed that the annual numbers of published articles from Japan and Taiwan remained steady, but those from Mainland China and South Korea increased linearly from 2006 to 2015, respectively ( $\mathrm{r}=0.91$ for Mainland China, $\mathrm{r}=0.82$ for South Korea, $\mathrm{p}<0.05$; figure 1). Further analysis confirmed that the growth of publication quantity from Mainland China and South Korea did not fulfil Price's law, because the square of correlation coefficient for exponential fitting was similar to that for linear fitting $\left(\mathrm{R}^{2}=0.788\right.$ vs $\mathrm{R}^{2}=0.827$ for Mainland China, $\mathrm{R}^{2}=0.710$ vs $\mathrm{R}^{2}=0.668$ for South Korea).

\section{Publication activity in relation to socioeconomic factors}

A previous study showed that the socioeconomic factor GDP strongly influenced the number of publications in the urology field, ${ }^{5}$ so we investigated whether GDP correlates with the transplantation publications in the four countries (areas). As illustrated in figure 2, there was a strongly positive correlation between the annual number of transplantation publications with GDP in Mainland China $(r=0.88, \mathrm{p}<0.05)$ and South Korea $(r=0.66, \mathrm{p}<0.05)$. However, the annual number of publications did not correlate with GDP in Japan and Taiwan.

\section{Classification of articles by study design and transplantation site}

In respect of study design, the total number of clinical trials from Mainland China was slightly higher than that from Japan, but was remarkably higher than that from South Korea or Taiwan. A similar phenomenon was

Table 2 Articles and proportion of total articles among Mainland China, Japan, South Korea and Taiwan from 2006 to 2015

\begin{tabular}{|c|c|c|c|c|}
\hline Country & Transplantation articles & Proportion of world* & Total articlest & Proportion of total articles $¥$ \\
\hline Japan & 3694 & 7.8 & 763514 & 0.48 \\
\hline Mainland China & 2778 & 5.9 & 1641246 & 0.17 \\
\hline Korea & 1643 & 3.5 & 419561 & 0.39 \\
\hline Taiwan & 951 & 2.0 & 231137 & 0.41 \\
\hline World & 47141 & & & \\
\hline
\end{tabular}


found in a RCT. However, the researchers from Japan published more case reports than did those from Mainland China, South Korea or Taiwan (figure 3). In respect of transplantation site, organ transplantation articles including the kidney, liver, lung and pancreas from Japan were the highest, followed by Mainland

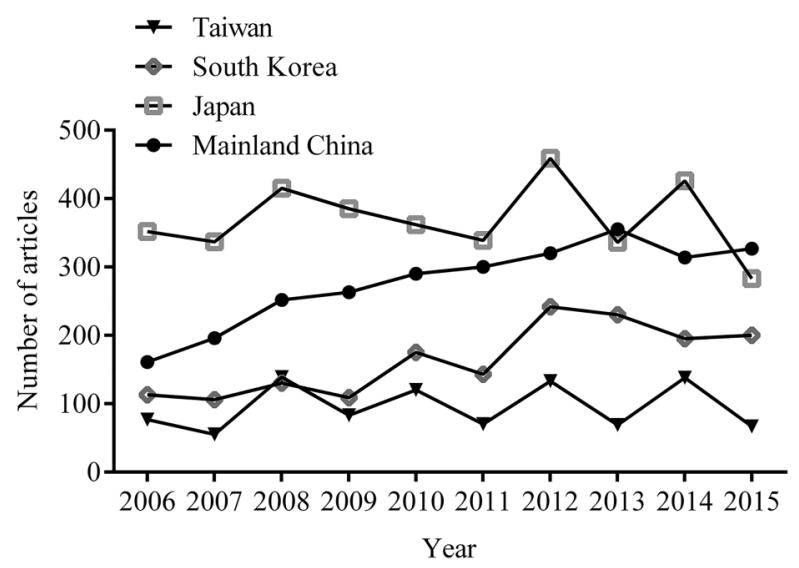

Figure 1 Trends in published transplantation articles by researchers from Mainland China, Japan, South Korea and Taiwan from 2006 to 2015.
China, South Korea and Taiwan. However, in the heart transplantation field, researchers from Mainland China published more articles than did those from Japan, Taiwan and South Korea (figure 3).

\section{Impact factor}

According to the 2014 JCR, all 25 journals in the transplantation field had an impact factor. As seen in table 3, the accumulated impact factor of articles from Japan (9677.5) was higher than that from Mainland China (6662.4), South Korea (3973.5) or Taiwan (2137.3). Only the differences between Japan and South Korea or Taiwan were significant $(p<0.05)$. The articles of Japan had the highest average impact factor (2.6), followed by Mainland China (2.4), South Korea (2.4) and Taiwan (2.2), but no significant differences were observed among the four countries (areas).

\section{Citations}

Total citations to the published articles from 2006 to 2015 in Japan were the highest (35 663 citations), followed by those from Mainland China (25 070 citations), South Korea (15 164 citations) and Taiwan (8657 citations), but only the differences between Taiwan and
Figure 2 Influence of GDP on transplantation publications from 2006 to 2015. GDP, gross domestic product.
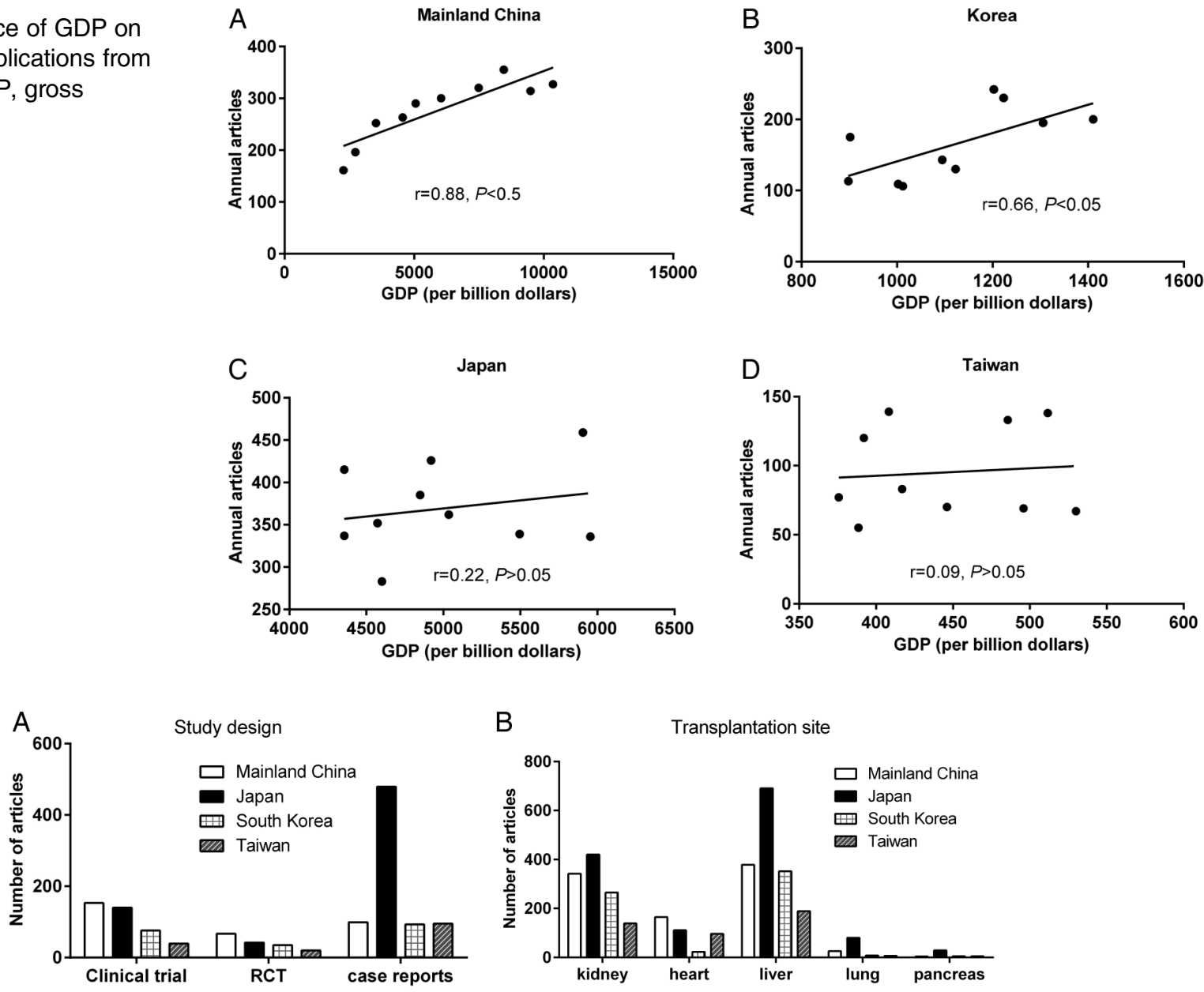

Figure 3 Classification of articles by study design and transplantation site from Mainland China, Japan, South Korea and Taiwan. RCT, randomised controlled trial. 
Japan or Mainland China were significant $(\mathrm{p}<0.05)$. Similarly, Japan had the highest average number of citations to each article (9.7), followed by South Korea (9.2), Taiwan (9.1) and Mainland China (9.0), but these differences of the average citation among the four countries (areas) were not statistically significant (table 4).
High-impact transplantation journals

Since the number of articles in high-impact journals often represents the scientific research level of one country in the field, we compared the differences in the number of articles in the top 10 transplantation journals between four countries (areas). A total of 4050 articles

Table 3 Accumulated and average impact factor of articles published by transplantation journals by researchers from Mainland China (ML), Japan (JP), South Korea (KR) and Taiwan (TW) from 2006 to 2015

\begin{tabular}{|c|c|c|c|c|c|c|c|c|}
\hline \multirow[b]{2}{*}{ Year } & \multicolumn{4}{|c|}{ Accumulated impact factor } & \multicolumn{4}{|c|}{ Average impact factor } \\
\hline & ML & JP & KR & TW & $\overline{M L}$ & JP & KR & TW \\
\hline 2006 & 336.5 & 1038.7 & 289.8 & 176.7 & 2.1 & 3.0 & 2.6 & 2.3 \\
\hline 2007 & 461.3 & 983.7 & 302.8 & 147.5 & 2.4 & 2.9 & 2.9 & 2.7 \\
\hline 2008 & 540.4 & 1125.1 & 299.0 & 253.3 & 2.1 & 2.7 & 2.3 & 1.8 \\
\hline 2009 & 643.0 & 989.1 & 310.8 & 227.8 & 2.4 & 2.6 & 2.9 & 2.7 \\
\hline 2010 & 674.4 & 963.2 & 431.5 & 257.5 & 2.3 & 2.7 & 2.5 & 2.1 \\
\hline 2011 & 695.2 & 932.1 & 405.8 & 203.5 & 2.3 & 2.7 & 2.8 & 2.9 \\
\hline 2012 & 843.8 & 1144.8 & 511.8 & 243.3 & 2.6 & 2.5 & 2.1 & 1.8 \\
\hline 2013 & 825.4 & 851.9 & 470.4 & 185.3 & 2.3 & 2.5 & 2.0 & 2.7 \\
\hline 2014 & 826.7 & 936.5 & 461.1 & 254.5 & 2.6 & 2.2 & 2.4 & 1.8 \\
\hline 2015 & 815.8 & 712.5 & 490.4 & 187.9 & 2.5 & 2.5 & 2.5 & 2.8 \\
\hline Total & 6662.4 & 9677.5 & 3973.5 & 2137.3 & 2.4 & 2.6 & 2.4 & 2.2 \\
\hline
\end{tabular}

Table 4 Total citations and average citation per article from Mainland China (ML), Japan (JP), South Korea (KR) and Taiwan (TW) from 2006 to 2015

\begin{tabular}{|c|c|c|c|c|c|c|c|c|}
\hline \multirow[b]{2}{*}{ Year } & \multicolumn{4}{|c|}{ Total citations } & \multicolumn{4}{|c|}{ Average citation } \\
\hline & $\overline{\mathrm{ML}}$ & $\mathbf{J P}$ & KR & TW & $\overline{\mathrm{ML}}$ & JP & KR & TW \\
\hline 2006 & 2506 & 6065 & 2313 & 1200 & 15.6 & 17.2 & 20.5 & 15.6 \\
\hline 2007 & 3612 & 5424 & 2032 & 795 & 18.4 & 16.1 & 19.2 & 14.5 \\
\hline 2008 & 3642 & 5678 & 1889 & 1516 & 14.5 & 13.7 & 14.5 & 10.9 \\
\hline 2009 & 3723 & 4931 & 1920 & 1331 & 14.2 & 12.8 & 17.6 & 16.0 \\
\hline 2010 & 3126 & 3848 & 2163 & 1320 & 10.8 & 10.6 & 12.4 & 11.0 \\
\hline 2011 & 2735 & 3055 & 1608 & 989 & 9.1 & 9.0 & 11.2 & 14.1 \\
\hline 2012 & 2741 & 3234 & 1676 & 749 & 8.6 & 7.0 & 6.9 & 5.6 \\
\hline 2013 & 1762 & 2162 & 935 & 420 & 5.0 & 6.4 & 4.1 & 6.1 \\
\hline 2014 & 946 & 1034 & 469 & 275 & 3.0 & 2.4 & 2.4 & 2.0 \\
\hline 2015 & 277 & 232 & 159 & 62 & 0.8 & 0.8 & 0.8 & 0.9 \\
\hline Total & 25070 & 35663 & 15164 & 8657 & 9.0 & 9.7 & 9.2 & 9.1 \\
\hline
\end{tabular}

Table 5 Articles published in the high-impact transplantation journals by researchers from Mainland China (ML), Japan (JP), South Korea (KR) and Taiwan (TW) from 2006 to 2015

\begin{tabular}{|c|c|c|c|c|c|c|c|c|}
\hline Rank & Journal & ISSN & IF & ML & JP & KR & TW & total \\
\hline 1 & Journal of Heart and Lung Transplantation & $1053-2498$ & 6.65 & 36 & 85 & 8 & 6 & 135 \\
\hline 2 & American Journal of Transplantation & $1600-6135$ & 5.683 & 70 & 134 & 27 & 16 & 247 \\
\hline 3 & Liver Transplantation & $1527-6465$ & 4.241 & 95 & 152 & 95 & 37 & 379 \\
\hline 4 & Transplantation & 0041-1337 & 3.828 & 158 & 308 & 101 & 62 & 629 \\
\hline 5 & Transplantation Reviews & $0955-470 x$ & 3.816 & 7 & 4 & & 1 & 12 \\
\hline 6 & Stem Cells and Development & $1547-3287$ & 3.727 & 273 & 116 & 139 & 24 & 552 \\
\hline 7 & Nephrology Dialysis Transplantation & 0931-0509 & 3.577 & 215 & 371 & 138 & 110 & 834 \\
\hline 8 & Bone Marrow Transplantation & 0268-3369 & 3.57 & 78 & 187 & 61 & 13 & 339 \\
\hline 9 & Biology of Blood and Marrow Transplantation & $1083-8791$ & 3.404 & 87 & 129 & 51 & 10 & 277 \\
\hline \multirow[t]{2}{*}{10} & Cell Transplantation & 0963-6897 & 3.127 & 181 & 240 & 104 & 121 & 646 \\
\hline & Total & & 41.623 & 1200 & 1726 & 724 & 400 & 4050 \\
\hline
\end{tabular}


from the four countries (areas) were published in the 10 top-ranking transplantation journals. Among them, 65.7\% (2661/4050) were in the four high-impact journals: Transplantation, Stem Cells and Development, Nephrology Dialysis Transplantation and Cell Transplantation (table 5). Researchers from Japan published the most articles $(1726,42.6 \%)$ in the 10 top-ranking transplantation journals, followed by Mainland China (1200, 29.6\%), South Korea $(724,17.9 \%)$ and Taiwan $(400,9.9 \%)$.

\section{Popular transplantation journals}

The popular journals for researchers in the four countries (areas) are listed in table 6. Surprisingly, the top 10 popular journals published $\sim 80 \%$ articles from all four countries (areas). The most popular journal for all four countries (areas) was the same: Transplantation Proceedings. Additionally, the other four popular journals are the same in all four countries (areas): Nephrology Dialysis Transplantation, Transplantation, Artificial Organs and Liver Transplantation. These results suggested that Mainland China, Japan, South Korea and Taiwan had an extremely similar submission choice.

\section{DISCUSSION}

To the best of our knowledge, this is the first study evaluating the contribution of authors from Mainland China, Japan, South Korea and Taiwan in the East Asia region to transplantation research. We found that researchers from Japan published the most articles on transplantation indexed in the WOS during 2006-2015, followed by Mainland China, South Korea and Taiwan. Transplantation productivity in East Asia is highly skewed, since Japan and Mainland China jointly account for $\sim 70 \%$ of the articles on transplantation. Other reports using the bibliometric tool for research assessment have demonstrated similar results in other medical subjects. ${ }^{9}$ Countries with a large population size such as Mainland China and Japan had a higher number of transplantation research output. GDP, research and development expenditure, healthcare expenditure and the number of researchers are potential factors related to enhanced research output. ${ }^{5610}$

Other indicators of Japan were also the highest, including accumulated impact factor, accumulated citations, articles in the high-impact journals, followed by Mainland China, South Korea and Taiwan. It is not surprising because there are positive correlations between the number of publications and the accumulated impact factor, accumulated citations or articles in the highimpact journals. ${ }^{5} 11 \quad 12$ Additionally, it is worth noting that the average impact factor and average citation of Mainland China is the lowest among four countries (areas). It suggested that transplantation researchers from Mainland China may sacrifice quality for quantity as demonstrated by other reports. ${ }^{13} 14$

Interestingly, the annual number of articles from Mainland China and South Korea showed a linear increase during 2006-2015, but those from Japan and Taiwan remained stable. One reason for this is the

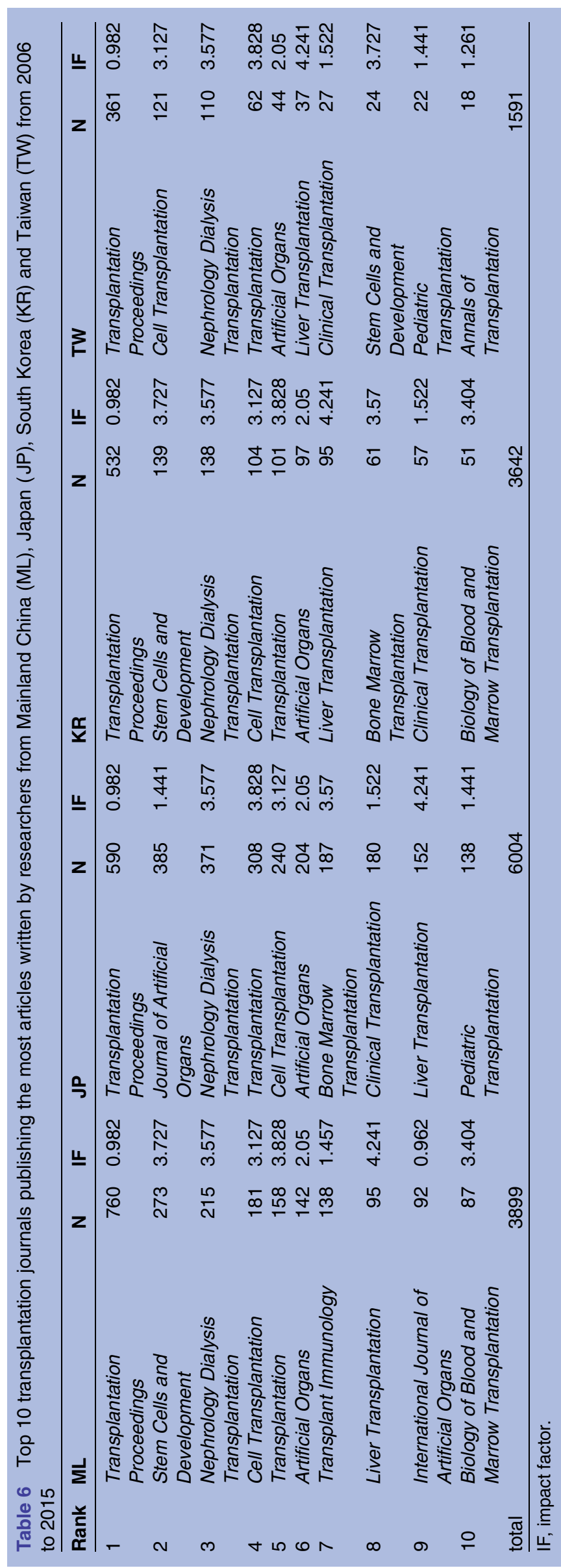


continuous increase in GDP in Mainland China and South Korea. As shown in figure 2, we then observed that GDP showed a strongly positive correlation with the annual number of articles. Other factors such as incentive award programmes and professional career requirements would definitely stimulate research output. ${ }^{10}$ For example, some institutions in Mainland China offer substantial money (about US $\$ 1500$ per impact factor) to papers published in high-impact journals. Besides, the number of transplantation clinicians and centres may influence the research output of a country, but insufficient data did not permit us to investigate that problem.

In terms of study design, authors from Mainland China contributed to the most clinical trials and RCTs. There are several reasons for this. First, China with a population over 1.3 billion has a huge number of potential candidates for those trials. Second, clinical trials in China are much cheaper. ${ }^{15}{ }^{16}$ In respect of transplantation site classified by organ, Mainland China had the largest number of patients with end-stage diseases and more cases of organ transplantation than Japan, but articles on organ transplantation from Mainland China were fewer than those from Japan, with the exception of heart transplantation. The vast difference in the specialist surgical workforce between the two countries might be the reason for this effect. ${ }^{17}$ The specialist surgical workforce was 2910 and 14833 per 100000 population in Mainland China and Japan, respectively (data from World Bank, http:// data.worldbank.org.cn). Besides, a centralised assignment of funds to specific research areas and a better use of related resources may be another reason for this effect. ${ }^{5}$

There are some limitations in our study. First of all, the journals in our sample were selected from the transplantation category of the 2015 SCIE, but some relevant journals were excluded in this index. Bibliometric analyses in other medical disciplines confirmed that results of category-oriented assessments of published articles were not basically changed even if disciplinerelated articles published in other journals were additionally considered. ${ }^{18} 19$ Therefore, we think our results could reflect research activities on transplantation. Furthermore, the accumulated and average impact factors were tabulated according to the impact factor of JCR 2014. However, it is worth noting that the impact factor of the journals varied each year. Therefore, the accumulated and average impact factors in this study are only estimations, but they are still likely to represent their trend since the alterations in the impact factor of most journals were relatively small in the past decade. Despite these limitations, we still believe that the results of our analysis were sufficient to represent the accurate situation on transplantation from Mainland China, Japan, South Korea and Taiwan in East Asia.

In conclusion, our study demonstrated the publication characteristics in the transplantation field in the East Asia region over the past decade. Most bibliometric indicators of transplantation articles from Mainland China were superior to those from South Korea and Taiwan, but were inferior to those from Japan. Additionally, the results showed that the socioeconomic factor GDP is a potential driver for research productivity in the transplantation field.

Contributors Q-HP and Q-JL jointly conceived and designed the study, performed the statistical analyses and prepared the manuscript. H-YS revised the paper. All authors read and approved the final manuscript.

Funding This research received no specific grant from any funding agency in the public, commercial or not-for-profit sectors.

Competing interests None declared.

Provenance and peer review Not commissioned; externally peer reviewed.

Data sharing statement No additional data are available.

Open Access This is an Open Access article distributed in accordance with the Creative Commons Attribution Non Commercial (CC BY-NC 4.0) license, which permits others to distribute, remix, adapt, build upon this work noncommercially, and license their derivative works on different terms, provided the original work is properly cited and the use is non-commercial. See: http:// creativecommons.org/licenses/by-nc/4.0/

\section{REFERENCES}

1. Aslani J, Khedmat $\mathrm{H}$, Assari $\mathrm{S}$, et al. Transplantation research in Iran: a bibliometric study. Transplant Proc 2007;39:788-9.

2. Bas K, Dayangac M, Yaprak O, et al. International collaboration of Turkey in liver transplantation research: a bibliometric analysis. Transplant Proc 2011;43:3796-801.

3. Eshraghi M, Habibi G, Rahim MB, et al. Bibliometric analysis of lung transplantation research articles. Thorac Cardiovasc Surg 2011;59:108-14.

4. Nourbala MH, Taheri S, Habibi R, et al. "Transplantation" research output by Muslim nations: current status, trends and future outlook. Ann Transplant 2008;13:21-7.

5. Oelrich B, Peters R, Jung K. A bibliometric evaluation of publications in urological journals among European Union countries between 2000-2005. Eur Urol 2007;52:1238-48.

6. Wiysonge CS, Uthman OA, Ndumbe PM, et al. A bibliometric analysis of childhood immunization research productivity in Africa since the onset of the Expanded Program on Immunization in 1974. BMC Med 2013;11:66.

7. López-Muñoz F, Sim K, Shen WW, et al. A bibliometric study of scientific research conducted on second-generation antipsychotic drugs in Singapore. Singapore Med J 2014;55:24-33.

8. López-Muñoz F, Shen WW, Shinfuku N, et al. A bibliometric study on second-generation antipsychotic drugs in the Asia-Pacific region. $J$ Exp Clin Med 2014;6:111-17.

9. Li M, Liu X, Zhang L. Scientific publications in public, environmental and occupational health journals by authors from China, Japan and Korea in East Asia: a 10-year literature survey from 2003 to 2012. Int J Occup Environ Health 2015;28:663-73.

10. Man H, Xin S, Bi W, et al. Comparison of publication trends in dermatology among Japan, South Korea and Mainland China. BMC Dermatol 2014;14:1.

11. Lao LF, Daubs MD, Phan KH, et al. Comparative study of scientific publications in orthopedics journals originating from USA, Japan and China (2000-2012). Acta Cir Bras 2013;28:800-6.

12. Li J, Gao XH, Bian Q, et al. Comparative study of scientific publications in urology and nephrology journals originating from USA, China and Japan (2001-2010). PLOS ONE 2012;7:e42200.

13. $\mathrm{Xu} \mathrm{J,} \mathrm{Mao} \mathrm{ZG,} \mathrm{Kong} \mathrm{M,} \mathrm{et} \mathrm{al.} \mathrm{Scientific} \mathrm{publications} \mathrm{in} \mathrm{nephrology}$ and urology journals from Chinese authors in East Asia: a 10-year survey of the literature. PLOS ONE 2011;6:e14781.

14. Li G, Hu LH, Liao Z, et al. Scientific publications in pharmacology and pharmacy journals from Chinese authors in various parts of North Asia: a 10-year survey of the literature. J Int Med Res 2010;38:750-9.

15. Mervis J. Epidemiology. China's unique environment favors large intervention trials. Science 1995;270:1149-51.

16. Cheng TO. Cardiology in contemporary China: an update. Int J Cardiol 2008;126:147-59.

17. White SL, Hirth $\mathrm{R}$, Mahíllo $\mathrm{B}$, et al. The global diffusion of organ transplantation: trends, drivers and policy implications. Bull World Health Organ 2014;92:826-35.

18. Boldt J, Maleck W, Koetter KP. Which countries publish in important anesthesia and critical care journals? Anesth Analg 1999;88:1175-80.

19. de Jong JW, Schaper W. The international rank order of clinical cardiology. Eur Heart J 1996;17:35-42. 